\title{
0 Uso da Tecnologia QR Code e de 0utros Recursos Digitais em Estudos de Invertebrados
}

\author{
Renée Soibelman'; Oscar Rocha-Barbosal
}

$\triangle$ reneesoibelman@hotmail.com

1. Universidade do Estado do Rio de Janeiro, Maracanã, Rio de Janeiro, Brasil.

\author{
Histórico do Artigo: \\ Recebido em: 06 de junho de $2020 \quad$ Aceito em: 16 de setembro de $2020 \quad$ Publicado em: 30 de abril de 2021
}

\begin{abstract}
Resumo: Este artigo tem como objetivo disponibilizar uma metodologia de uso da tecnologia $Q R$ Code e outros recursos digitais na construção do conhecimento, em estudos de invertebrados. Através de uma sequência didática, em uma página da Web, o projeto irá proporcionar um enfoque investigativo no estudo deste grupo zoológico. A ideia desse projeto surgiu da necessidade de se produzir um recurso tecnológico para se inserir o conteúdo de estudos dos invertebrados utilizando as tecnologias da informação e comunicação (TICs), tão presentes no cotidiano dos alunos. 0 professor, através de uma aula diversificada, irá conduzir os alunos a atividades e pesquisas, que serão apresentadas por meio do $Q R$ Code e links do site, objetivando promover nos discentes as competências de leitura, construções de textos e motivação para o estudo de zoologia dos invertebrados. 0 smartphone sendo utilizado como recurso didático será um diferencial para os alunos já que é presença constante no seu cotidiano. No cenário atual da Covid 19, em que as aulas presenciais foram suspensas, o uso de sequência didática online poderá auxiliar os docentes como metodologia de ensino. Essa sequência didática também ficará disponibilizada em pôsteres com os códigos $Q R$, de forma que somente com o aparelho celular com acesso a internet e com leitor de código, o professor poderá conduzir a sequência didática. Como sugestões para trabalhos futuros essa metodologia poderia ser utilizada para qualquer conteúdo de Biologia ou em qualquer outra disciplina.

Palavras-chave: Recursos digitais no ensino, Construção do conhecimento, Zoologia dos invertebrados, Smartphone, Mídias em educação.
\end{abstract}

\section{QR Code Technology and Other Digital Resources in Invertebrate Studies}

\begin{abstract}
This article aims to use QR Code technology and other digital resources in the construction of knowledge in invertebrate studies. With a didactic sequence, available on a web page, the project will provide an investigative focus on the study of this zoological group. The idea for this project arose from the need to produce a didactic resource that could insert the content of invertebrate studies using the information and communication technologies (ICTs), extremelly present in the students' daily lives. The teacher, through a dinamic class, will lead students to activities and research, which will be presented through the QR Code and website links, with the objective to promote students' reading skills, text construction and motivation for studying the zoology of invertebrates. Using the smartphone as a teaching resource will be a differential for students, since it is a constant presence in their daily lives. In the current scenario of Covid 19, in which face-to-face classes have been suspended, the use of online didactic sequence may help teachers as a useful methodology. This didactic sequence will also be available on posters with $Q R$ codes, requiring only the cell phone with internet access and with code reader to be used. As suggestions for future work, this methodology could be used for any Biology content or any other discipline.

Keywords: Digital resources in teaching, Knowledge construction, Zoology of invertebrates, Smartphone, Media in education.
\end{abstract}




\section{El Uso de Tecnología de Códigos Qr y 0tros Recursos Digitales en Estudios de Invertebrados}

Resumen: Este artículo tiene como objetivo utilizar la tecnología del Código $Q R$ y otros recursos digitales en la construcción del conocimiento, en estudios de invertebrados. A través de una secuencia didáctica, disponible en una página web, el proyecto proporcionará un enfoque de investigación en el estudio de este grupo zoológico. La idea de este proyecto surgió de la necesidad de producir un recurso didáctico para insertar contenido de estudio de invertebrados utilizando tecnologías de información y comunicación (TIC), tan presentes en la vida cotidiana de los estudiantes. El profesor, a través de una clase diversificada, guiará a los estudiantes a actividades e investigaciones, que se presentarán a través del Código $Q \mathrm{R}$ y enlaces a sitios web, con el objetivo de promover en los estudiantes las habilidades de lectura, la construcción de textos y la motivación para el estudio de la zoología. de invertebrados. El móvil que se utiliza como recurso educativo será un diferencial para los estudiantes, ya que es una presencia constante en su vida diaria. En el escenario actual de Covid 19, en el que se suspendieron las clases presenciales, el uso de la secuencia didáctica en línea puede ayudar a los maestros como metodología de enseñanza. Esta secuencia didáctica también estará disponible en carteles con códigos QR, que solo requieren el uso del teléfono celular con acceso a internet y con lector de códigos. Como sugerencias para trabajos futuros, esta metodología podría usarse para cualquier contenido de biología o en cualquier otra asignatura.

Palabras clave: Recursos digitales en la enseñanza, Construcción del conocimiento, Zoología de invertebrados, Teléfono celular, Medios en educación.

\section{INTRODUÇ̃̃o}

A maior parte dos conteúdos de Zoologia dos livros didáticos do Ensino Médio são fragmentados e limitam o estudo interdisciplinar, tornando-os abstratos e de difícil aprendizagem pelo excesso de termos e conceitos biológicos. Estabelecendo um quadro de elementos que dificultam a autonomia do plano de curso do professor, em 2012, foi elaborado 0 currículo mínimo de Biologia (Rio de Janeiro, 2012). Esse plano tinha como prioridade a criação de uma base estadual comum, atendendo o que estava estabelecido pelos Parâmetros Curriculares Nacionais (Brasil, 2002). Ele, estabelece também, a sequência de conteúdos que devem estar nos planos de curso da rede estadual. Dessa forma alguns professores, em encontros pedagógicos, questionavam a escassez de carga horária para se inserir vários conteúdos que sinalizavam como importantes ou interessantes para os alunos.

A partir desse contexto, o principal objetivo desse projeto foi o de apresentar uma proposta de produção recursos didáticos digitais, de forma que 0 aluno construa o seu conhecimento e elabore conceitos importantes sobre os filos dos invertebrados, resultando em uma aprendizagem significativa. Verificando a frequência do uso dos smartphones e essa ferramenta como facilitador de acesso às informações, temos como enfoque principal do projeto o uso do QR Code sendo utilizados em uma sequência didática. 
De acordo com Zabala (1998), antes de aplicar uma prática pedagógica os conteúdos devem ser organizados, de maneira que 0 conjunto de atividades propostas possibilite 0 processo ensino-aprendizagem. A sequência didática é definida como "um conjunto de atividades ordenadas, estruturadas e articuladas para a realização de certos objetivos educacionais, que têm um princípio e um fim conhecidos tanto pelos professores como pelos alunos." (ZABALA, 1998, p.18). Assim, ainda segundo o autor, o objetivo da sequência didática é:

[...] introduzir nas diferentes formas de intervenção aquelas atividades que possibilitem uma melhora de nossa atuação nas aulas, como resultado de um conhecimento mais profundo das variáveis que intervém do papel que cada uma delas tem no processo de aprendizagem dos meninos e meninas. (ZABALA 1998, p.54).

Muitas vezes um dos fatores que interferem na elaboração das aulas é a escassez de recursos em algumas escolas. Em se tratando em ensino de Biologia, há uma imensidão de termos de difícil compreensão. Dessa forma o processo de aprendizagem é um dos grandes desafios para os educadores. Krasilchik (2005, p.11), destaca que ..."a Biologia pode ser uma das disciplinas mais relevantes e merecedoras da atenção dos alunos, ou uma das disciplinas mais insignificantes e pouco atraentes, dependendo do que for ensinado e de como isso for feito". Por isso é muito importante ao selecionar o conteúdo e buscar a modalidade didática e recursos tecnológicos adequados para a aprendizagem ser significativa. Além disso devemos estar sempre buscando facilitar a aprendizagem do aluno porque segundo Magarão e colaboradores:

[...] o ensino de Ciências e de Biologia é repleto de conteúdos cujos conhecimentos e conceitos são de difícil compreensão e assimilação, tendo em vista seu nível de abstração e formas de representação. Somente para citar alguns dos desafios enfrentados, alguns exemplos destas dificuldades são oriundos de conceitos de difícil visualização, tais como elementos visíveis somente microscopicamente e/ou através de corantes e aos quais os alunos dificilmente têm acesso e de fenômenos que representam processos que se desenvolvem ao longo do tempo, mas que ficam impossíveis de serem compreendidos no período da sala de aula. (MAGARÃo et al., 2012).

Assim, fotos de textos, artigos da Web e vídeos do youtube ou de outras fontes, auxiliam muito a aprendizagem. 0 uso de slides e vídeos nas aulas de Biologia permite a observação de várias estruturas dos animais, a relação do ser vivo com o ambiente, sua locomoção e seus hábitos alimentares. 0 importante é o professor ter estratégias de planejamento e utilizar os recursos digitais sempre que oportuno.

Não podemos deixar de ressaltar que o smartphone é presença constante no cotidiano dos alunos e se tornou principal porta de entrada para o mundo digital para a maioria das 
pessoas. Segundo Serres (2013), por celular hoje se tem acesso a todas as pessoas, por GPS a todos os lugares e pela internet a todo saber. A maioria dos jovens de hoje possuem celulares e utilizam estes aparelhos para múltiplas finalidades. Segundo Moura (2009) há anos que o número de celulares superou o número de computadores pessoais.

0 telemóvel está a alterar as possibilidades e os aspectos práticos de muitos componentes da vida quotidiana. Está a mudar a natureza da comunicação, a afectar as identidades e as relações. Tem afectado também o desenvolvimento das estruturas sociais e as actividades econômicas e está a ter uma influência considerável na percepção que os utilizadores têm sobre si próprios e do mundo. (M0URA, 2009, p. 50).

Certamente não param de surgir novas possibilidades para o uso de celulares na educação. Alguns exemplos são: pesquisas, fotos para trabalhos escolares, vídeos e aplicativos para celular (App). Com a suspensão das aulas devido a Pandemia do Covid 19, muitas instituições escolares tiveram que se adequar ao ensino online e às tecnologias digitais, utilizando plataformas de aprendizagem como Google Classroom e o Hangouts Meet da Google suíte, para as transmissões e aulas ao vivo, por exemplo.

No projeto "0 uso da tecnologia do QR code e de outros recursos digitais, em estudos de invertebrados", os códigos QR foram utilizados para construção de palavras, frases, textos, links, de forma a elaborar uma interatividade com o uso do celular e tecnologias digitais para construção do conhecimento.

\section{METOD0LOGIA}

As etapas para elaboração desse projeto compreenderam a pesquisa bibliográfica, a seleção das principais características que foram utilizados para comparação morfológica e fisiológica dos invertebrados, a pesquisa sobre a utilização dos softwares e aplicativos que foram utilizados, a elaboração do material didático e a aplicabilidade do material produzido na construção do conhecimento sobre o grupo zoológico.

Durante a realização do projeto foram selecionadas imagens de alguns representantes de invertebrados. Foram feitas pesquisas sobre as principais características dos invertebrados, filogenia, zoonoses e das etapas do desenvolvimento embriológico. Para elaborar a sequência didática foram utilizados recursos digitais variados como slide, vídeo e a tecnologia QR Code para aplicativos em smartphones. Para produção de um vídeo foi utilizado o editor Powtoon, um 
programa que possibilita exportar imagens de slides do aplicativo Power point e criar vídeos com fotos e imagens e ainda, editar as legendas.

Foi construída uma página da Web através do Google Sites, na qual está disponibilizada uma sequência didática sobre o conteúdo do estudo dos invertebrados. As atividades para uso do QR Code localizadas na página da Web e estão disponibilizadas em pôsteres digitais.

0 professor também poderá utilizar esse material com o Datashow para uma atividade conjunta com a turma ou ainda ser utilizado em sala de informática. Caso não haja acesso à internet na escola, existe a opção dos pôsteres digitais que contém todas as etapas da sequência didática e que através do uso de um celular com acesso a internet 0 aluno faz as atividades ao escanear o código, que converte imediatamente em texto, links, em suma, o que estiver codificado.

0 QR Code foi criado por uma empresa automobilística, no Japão, em 1994 0 0bjetivo era criar um código que fosse rápido para catalogar todos os componentes e peças dos carros produzidos. Segundo a Denso Wavés Website, o QR do nome significa resposta rápida. 0 código de barras tradicional pode ter no máximo 20 dígitos, um QR Code pode armazenar até 7.089 caracteres, numa matriz 2-D, isto é, pode ser lido em duas direções horizontal ou vertical. Disponível em: https://www.qrcode.com/en/history/, com acesso em. 08/05/2020.

Os QR Codes são elaborados com diversos pixels pretos. Esses pequenos quadradinhos representam todo o conteúdo presente dentro do código e são chamados de módulos. Cada um dos quadradinhos tem funções específicas. Os três maiores quadrados que estão presentes nos cantos do código servem como uma ferramenta de orientação para informar onde estão os outros dados, além de ajudar para que o leitor consiga identificar o $Q R$ Code em qualquer posição (Figura 1). 

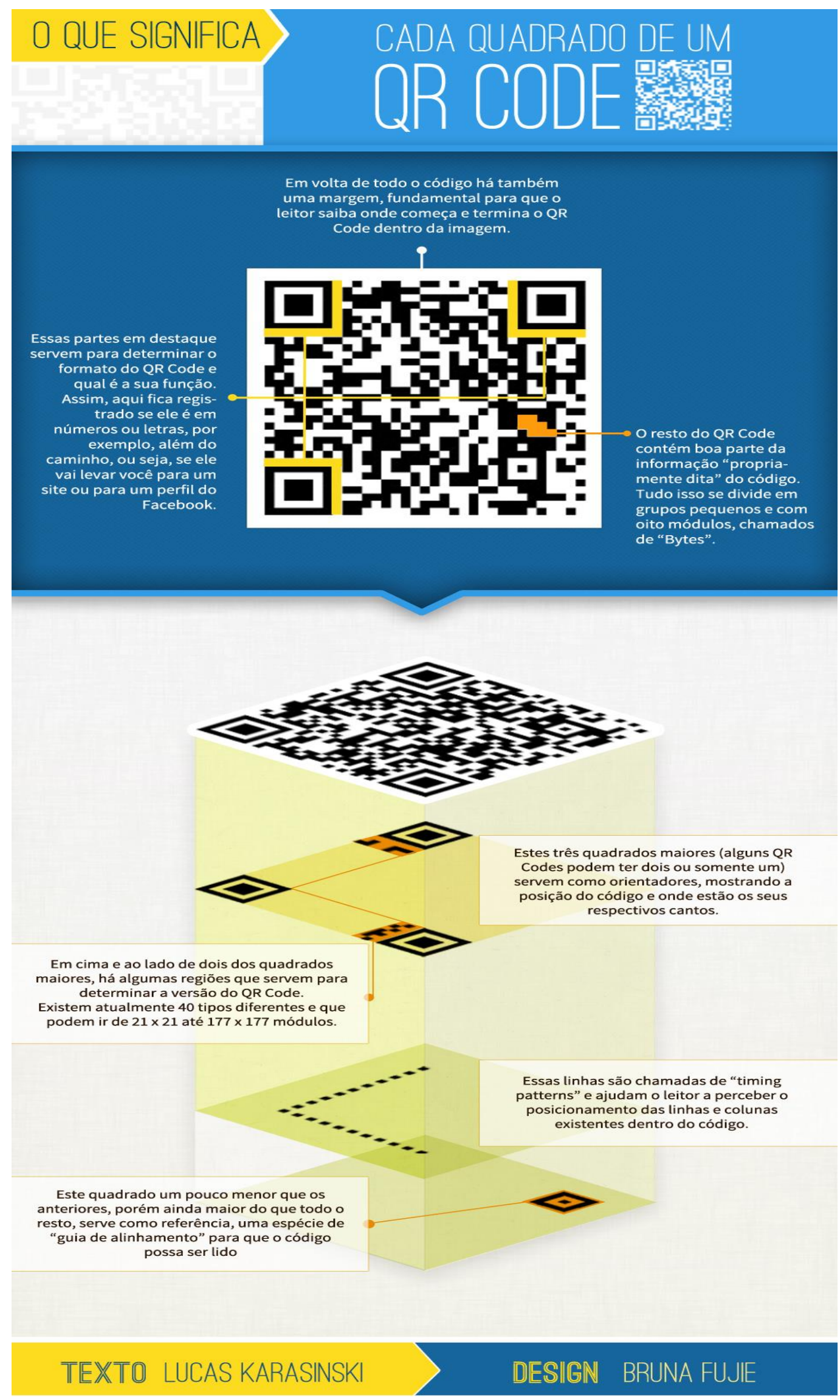

Figura 1. Imagem explicativa das partes de um $Q R$ Code.

Fonte: Infográfico Tecmundo, 2013. 
Para elaboração do $Q R$ Code foi utilizada uma página da web de versão gratuita para geração de códigos de barras 2D. 0 link de acesso à página é: https://qrcode.trustthisproduct.com/free-qr-code-generator.php?lang=pt.

As figuras 2 e 3 a seguir são fotos das páginas com etapas da geração de um QR Code.

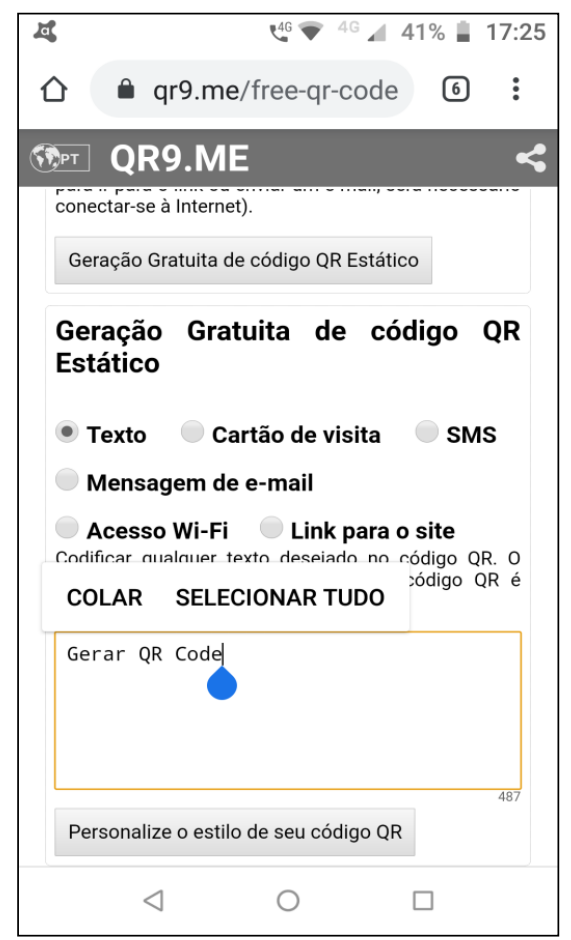

Figura 2. Foto da página da Web para geração de QR Code. Fonte: A autora, 2020.

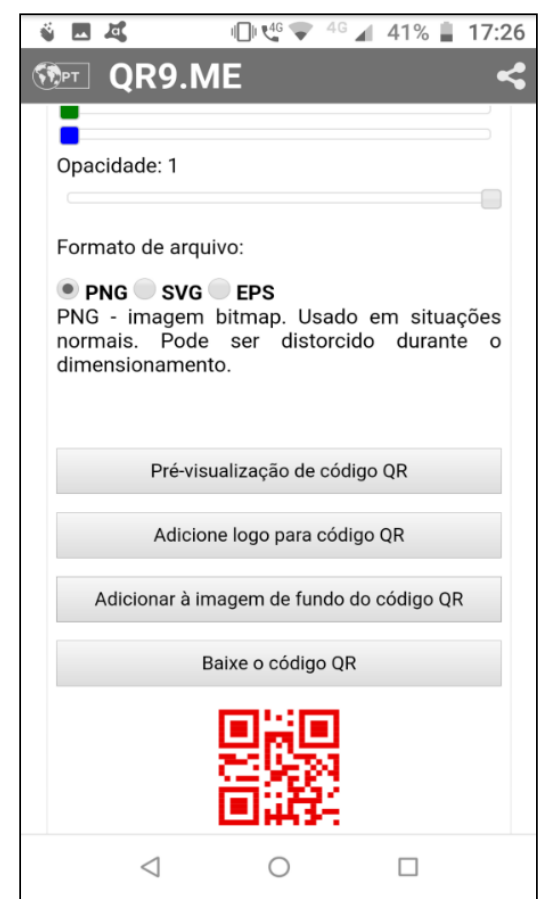

Figura 3. Foto da página da Web com $Q R$ Code sendo gerado. 
Fonte: A autora, 2020.

0 QR Code a seguir (figura 4) direciona você à página da Web que contém a sequência didática deste projeto.

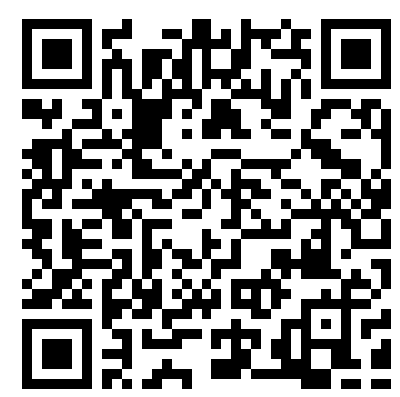

Figura 4. Imagem do QR Code de acesso ao site da sequência didática.

Fonte: A autora, 2020.

Como exemplo de um QR Code codificando um texto temos a figura 5. Os códigos possuem várias opções de formas e cores. Ao direcionar o leitor de $Q R$ Code do seu aparelho celular na figura 5 aparecerá a seguinte informação: "Não possuem sistema respiratório. As trocas gasosas ocorrem diretamente entre as células que constituem toda a estrutura corpórea e o ambiente". Figura 5. Imagem de QR Code com texto.

Fonte: A autora, 2020.

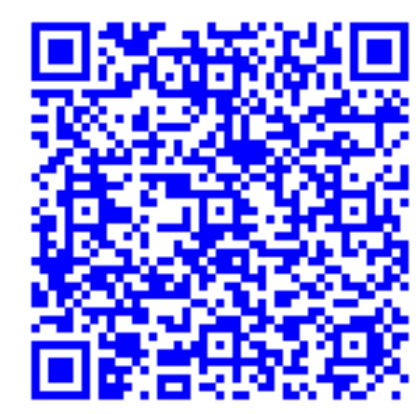

No decorrer da sequência didática foram utilizados tipos diferentes de Código QR buscando uma interatividade e com objetivo de diversificar a maneira dos alunos aprenderem novos conteúdos. Cabe ressaltar que na página da Web que contém a sequência didática os QR Codes estão nos tamanhos ideais para serem utilizados. A seguir temos figuras de dois pôsteres digitais (material impresso com as atividades da sequência didática). 0s pôsteres estão disponíveis na página da sequência didática e estão em PDF para impressão. 0 tamanho real dos pôsteres são: figura 6 (50 cm de largura e $40 \mathrm{~cm}$ de altura) e figura 7 (90 cm de largura e $60 \mathrm{~cm}$ de altura). 
Utilizando o QR Code investigativo

1-Em quais ambientes os invertebrados podem ser encontrados? Confira sua resposta.

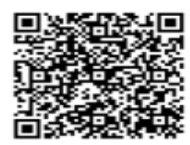

2-Use os links abaixo e pesquise exemplos de invertebrados aquáticos (marinhos e de água-doce), terrestres e parasitas.
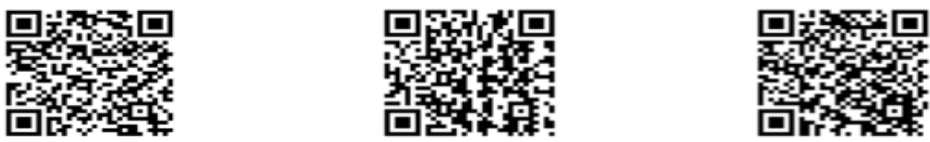

Confira se acertou.

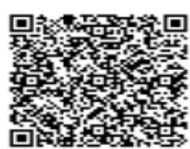

3-Quais são as modificações que um ovo ou zigoto sofre até atingir o tamanho e as funções de um indivíduo adulto?

Como será que surgem os tecidos, os órgãos e os sistemas?

Observe o esquema abaixo. Cada número corresponde a uma etapa

do desenvolvimento embrionário. Utilize o código QR e associe corretamente.
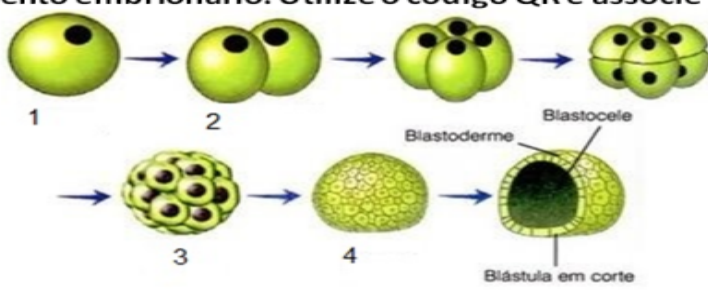

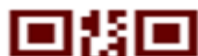

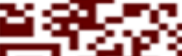

Fontions
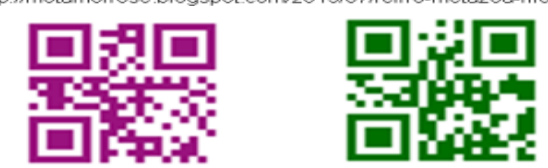

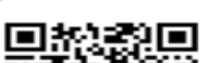

Confira se

acertou
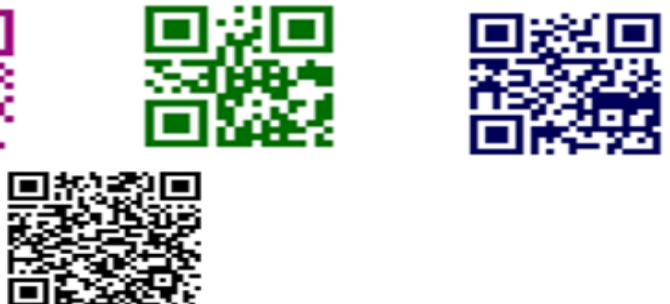

4-Após a mórula ocorre a formação da blástula, onde as células delimitam uma cavidade interna chamada blastocele, cheia de um líquido produzido pelas próprias células. Assista ao vídeo.

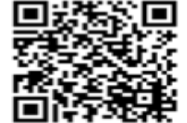

5-A partir da blástula, inicia a fase de gastrulação, onde embriáo começa a aumentar de tamanho e surge o intestino primitivo ou arquêntero e ocorre a diferenciação dos folhetos embrionários. Os folhetos darăo origem aos diferentes tecidos do corpo: ectoderme, endoderme e mesoderme. Ao lado o vídeo da gastrulação.

6-Animais diblásticos e triblásticos

Animais que apresentam dois folhetos embrionários: a ectoderme, (externo) e a endoderme, (interno). São chamados de diblásticos. Veja um exemplo.

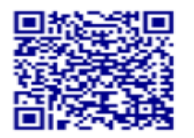

Eos animais que apresentam três folhetos embrionários: endoderme, mesodermeectoderme são emamados de

..........................

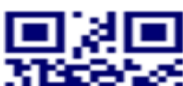
ate

7-Comparando a divisão dos planos corporais dos animais observamos que um animal pode apresentar simetria radial, bilateral ou não apresentar simetria. Pesquise o que é simetria.

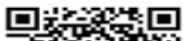

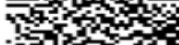

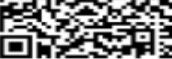

Agora acesse os códigos abaixo e diga qual desses animais possuem simetria Agralou bilateral.

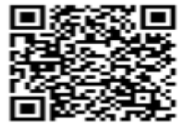

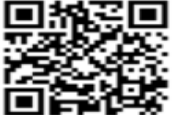

Confira se acertou

Figura 6. Pôster, "Utilizando o QR Code investigativo".

Fonte: A autora, 2020

Revista Internacional de Ciências, v. 11, n. 01, p. 61-77, jan-abr, 2021 


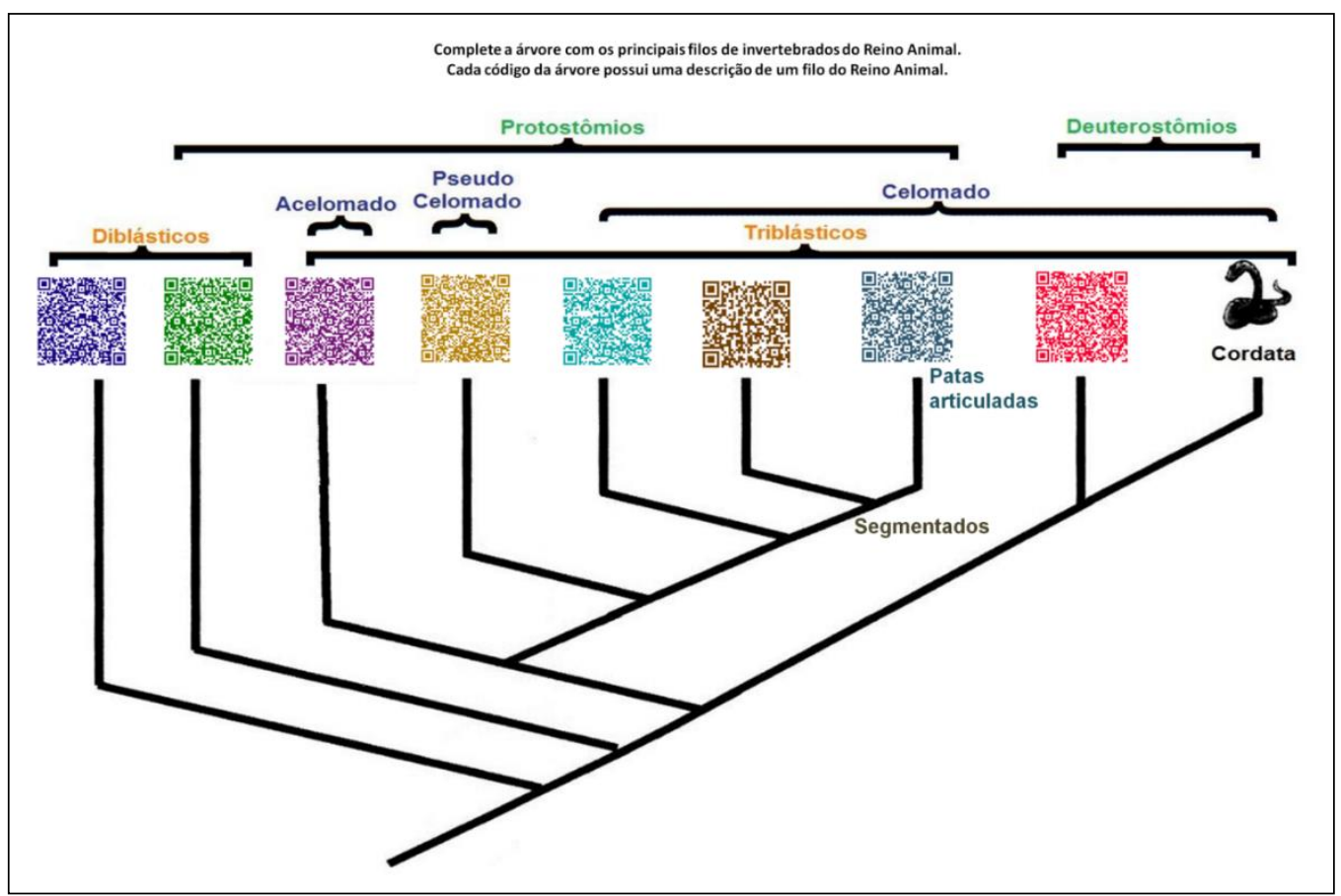

Figura 7. Pôster, "Árvore filogenética interativa".

Fonte: Adaptado de https://netnature.files.wordpress.com/2014/11/proto.jpg.

\section{RESULTADOS E DISCUSSÃ0}

Serão apresentadas as análises dos questionários atribuídos aos discentes do curso de Mestrado Profissional em Ensino de Biologia, Profbio, turma 2018, com objetivo de observar a aplicabilidade da metodologia em sala de aula. Foi considerado para a análise dos dados, as respostas e relatos dos professores. 0 objeto de estudo é a sequência didática que utiliza o $Q R$ Code e o smartphone, de modo a facilitar o aprendizado e inserir o conteúdo de invertebrados de forma interativa e investigativa. Em decorrência da Pandemia do COVID-19, as aulas foram suspensas como medida de combate à disseminação da doença, então conforme orientações da Comissão Nacional da Profbio, optamos por utilizar a estratégia metodológica de coleta de dados por meio da aplicação de um questionário on-line, do Google form.

Foram entrevistados dezoito professores, que puderam participar da sequência didática, fazer as atividades, opinar e verificar a viabilidade de utilização em suas aulas. Foi encaminhado para os professores participantes da pesquisa, por e-mail, o questionário e o Termo de Consentimento livre e esclarecido (TCLE), disponibilizado na plataforma Google Drive. É importante destacar que o projeto foi autorizado pelo Comitê de Ética em Pesquisa da UERJ, sob número CAAE 18062719.0.0000.5282 de 13/09/2019, aplicou-se a pesquisa, durante o mês de abril de 2020. 
A tabulação e sistematização dos dados foram realizadas pelo programa Excel, que possibilita a geração de gráficos e tabelas, garantindo uma melhor visualização e análise dos dados. Após a participação na sequência didática, os professores fizeram a validação da metodologia através do preenchimento de um questionário com perguntas subjetivas e objetivas. A pesquisa foi qualitativa e a análise dos resultados seguiu o discurso do sujeito coletivo que é uma técnica de tabulação e organização de dados qualitativos, desenvolvido por Lefevre e Lefevre no fim da década de 90 e que analisa as respostas recebidas das questões abertas da pesquisa, agrupando as de sentido semelhante e:

Estes conteúdos de mesmo sentido, reunidos num único discurso, por estarem redigidos na primeira pessoa do singular, buscam produzir no leitor um efeito de "coletividade falando"; além disso, dão lugar a um acréscimo de densidade semântica nas representações sociais, fazendo com que uma ideia ou posicionamento dos depoentes apareça de modo "encorpado", desenvolvido, enriquecido, desdobrado. (Lefevre, Lefevre e Marques, 2009, p. 1194).

Foi possível traçar um perfil dos professores participantes da pesquisa, com relação à atuação nas esferas, municipal, estadual, federal e particular de ensino. Para cada pergunta marcaram suas respostas como sim ou não. Dos dezoito participantes da pesquisa catorze responderam que lecionavam na Rede Estadual de Ensino. Seis professores disseram que lecionavam também na Rede Municipal de Ensino, três afirmaram que trabalhavam na Rede Particular de Ensino e somente um entrevistado trabalhava na Rede Federal de Ensino.

Gráfico 1 - Gráfico indicando em quais redes de ensino os professores lecionam.

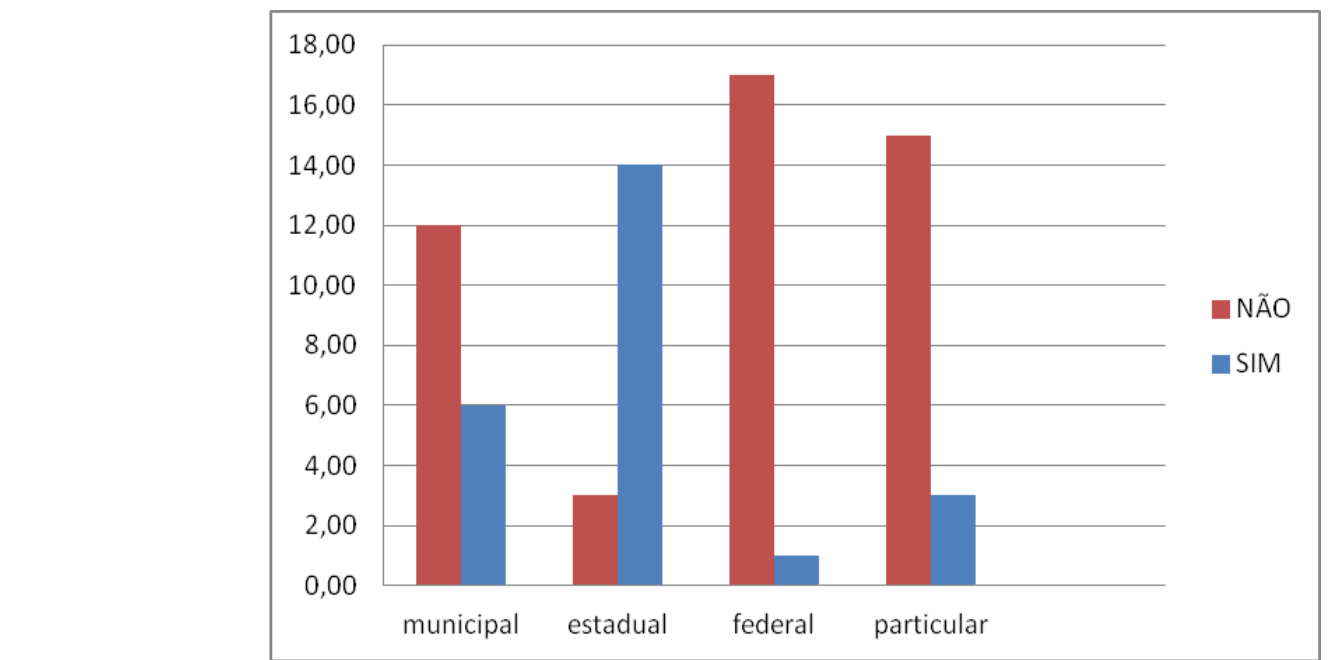

Fonte: A autora, 2020. 
Seguindo na sequência da pesquisa, os professores foram perguntados se no seu planejamento anual conseguiam inserir o conteúdo de invertebrados, apesar da implantação do currículo mínimo de Biologia em 2012. Ao serem entrevistados, dez responderam que inserem no planejamento o estudo dos invertebrados, dois relataram que conseguem inserir juntamente com outro conteúdo de ensino e seis disseram que não colocam o conteúdo de invertebrados no seu planejamento.

Gráfico 2. Os professores, no seu planejamento anual, conseguem inserir o conteúdo de invertebrado?

Fonte: A autora, 2020.

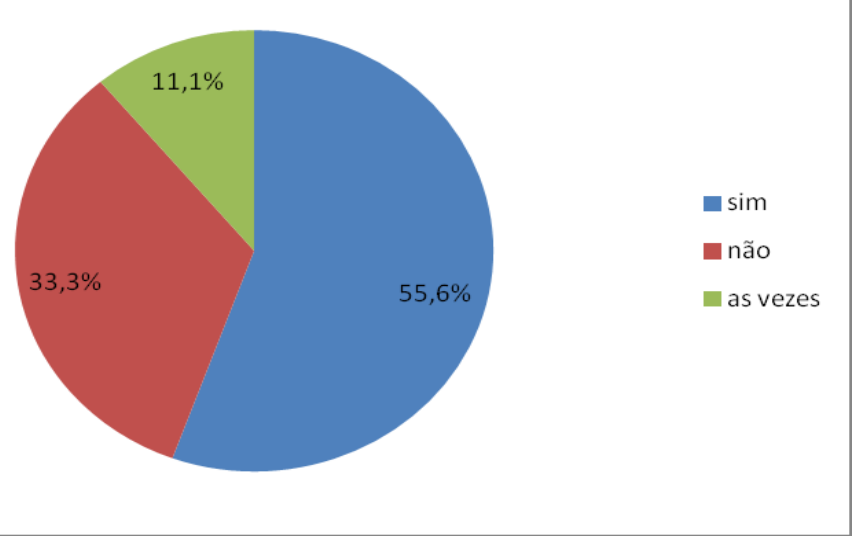

Perguntados se acham importante inserir o estudo dos invertebrados, utilizando uma aula interativa, para que o aluno consiga ter a oportunidade de conhecer a anatomia comparada e a embriologia do Reino Animal, $100 \%$ dos entrevistados sinalizaram que sim.

Gráfico 3. Se o professor acha importante inserir o conteúdo de invertebrados, utilizando uma aula interativa.

Fonte: A autora, 2020.

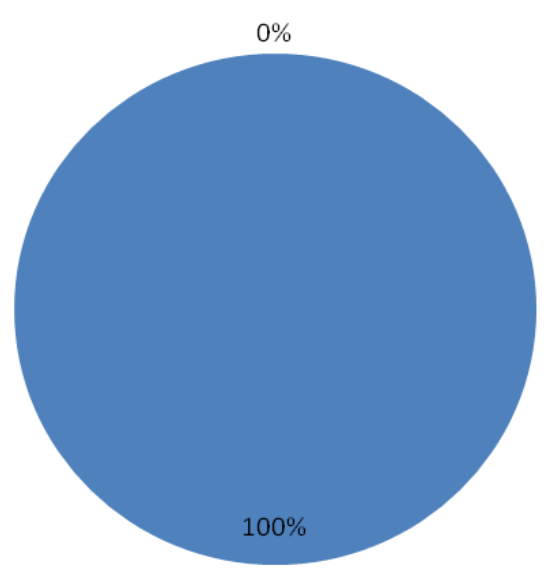

- $\operatorname{sim}$

घnão 
Um dos conteúdos do currículo mínimo do Estado do Rio de Janeiro para $02^{\circ}$ ano, no segundo bimestre, é o estudo das células e a diversidade dos tecidos e os sistemas do corpo humano. Perguntados em qual momento os professores utilizariam a Sequência Didática no seu plano de curso de Biologia do Ensino médio, dez professores responderam que o material didático poderia servir como uma introdução ao estudar os sistemas dos seres vivos. Quatro professores responderam que o material didático poderia auxiliar na compreensão das transformações que ocorrem após a fertilização e formação do embrião nos diversos grupos do reino animal. Três professores responderam que o material didático poderia ser utilizado antes do estudo dos tecidos animais para os alunos conhecerem como ocorre a diferenciação celular e formação de diversos tecidos nos diferentes grupos do Reino Animal. Um professor relatou que sinalizou a opção "outros”, pois acha ideal utilizar o estudo dos invertebrados juntamente com conteúdos de sistemática e evolução. Nenhum professor deixaria de utilizar esse produto no segundo ano do ensino médio.

Gráfico 4. Em qual momento você utilizaria a Sequência Didática no seu plano de curso de Biologia do Ensino médio?

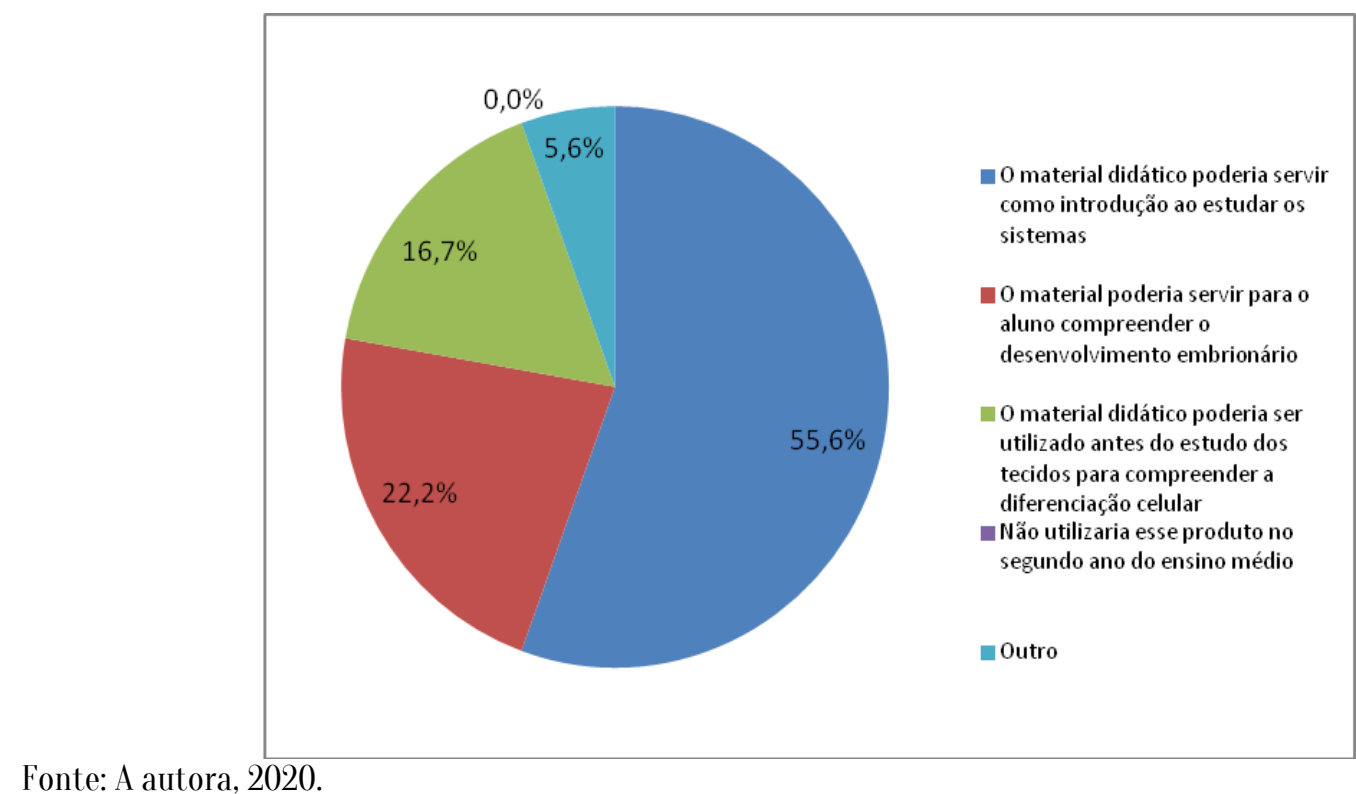

Quanto à dificuldade de utilização da metodologia, como acesso ao site, utilização da sequência didática e do questionário do formulário Google, os professores sinalizaram que conseguiram realizar todas as atividades. 
Gráfico 5. 0s professores encontraram dificuldade ao utilizar o material didático?

Fonte: A autora, 2020.
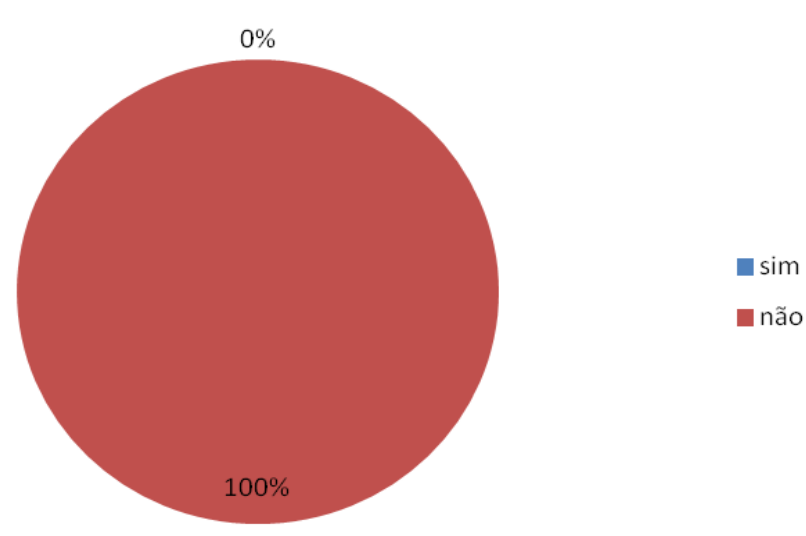

não

0s professores foram perguntados o que eles acharam de mais interessante sobre a utilização do Código QR em atividades educacionais. Seis professores disseram que não sabiam como gerar um QR Code. Cinco professores disseram que tinham conhecimento que o QR Code direcionava a sites, mas não sabiam que poderia estar em um Pôster e ser utilizado para direcionar a links do Youtube, por exemplo. Cinco professores disseram que já tinham utilizado QR Code como recurso pedagógico e dois professores não tinham conhecimento que o QR Code poderia codificar textos.

Gráfico 6. 0 que os professores acharam de mais interessante na metodologia do uso em atividades educacionais?

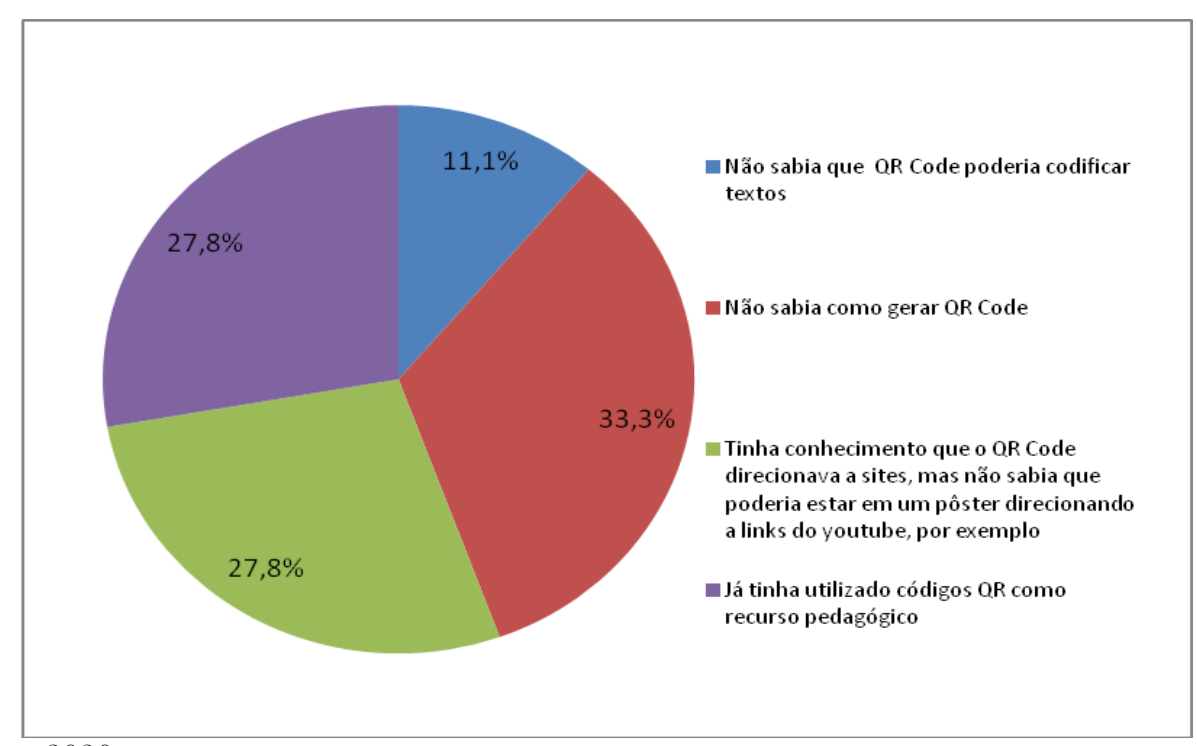

Fonte: A autora, 2020. 


\section{CONSIDERAÇÕES FINAIS}

No decorrer do projeto foi demonstrado que os professores concordam que aulas mais interativas utilizando recursos digitais as tornam mais atrativas. No que diz respeito ao uso do smartphone, o colocamos como um aliado e passível de se utilizar no contexto escolar, porém com reflexões importantes sobre a regulamentação do uso do telefone celular e respeitando a regra de cada unidade escolar. A sociedade atual está na era digital e temos percebido um crescente uso do telemóvel para as mais variadas funções. Por que rejeitar um recurso que pode ser um grande aliado no processo de construção de aprendizagem do aluno?

A minha visão como docente por mais de trinta anos não deixa dúvidas que temos que estar sempre nos reformulando e adequando aos novos desafios. No contexto do atual do cenário da Covid 19, onde as aulas presenciais foram suspensas, o uso de sequência didática (SD) online, poderá auxiliar os docentes, como metodologia de ensino. Além disso, mediante o ano letivo normalizado, o projeto "0 uso do QR Code e de outros recursos digitais, em estudos de invertebrados" poderá ser utilizado nas escolas pelo professor através dos pôsteres digitais que contém a SD, necessitando somente de alguns aparelhos celulares que possuam acesso a internet e o leitor de código QR.

0 conteúdo de Biologia é muito extenso e repleto de conceitos e termos difíceis, o projeto como recurso digital poderá ser um bom aliado na aprendizagem. A intenção é tornar o conteúdo disponível e passível de ser introduzido no planejamento escolar.

A partir do resultado da pesquisa realizada com os docentes verifiquei a viabilidade da utilização dos códigos QR em uma sequência didática. A sequência didática com utilização do QR Code e links do site, objetivou promover nos discentes, as competências de leitura, construções de textos, motivação para o estudo na aprendizagem de zoologia dos invertebrados, além da capacitação para construção e o uso dos códigos QR. Como sugestões para trabalhos futuros com essa metodologia, a mesma poderia ser utilizada para qualquer conteúdo de Biologia ou qualquer outra disciplina. Cabe também aprimorar e avaliar junto a vários docentes, os tutoriais propostos nessa SD, bem como a discussão acerca dos planos de curso e sequências de conteúdo. Acredito que o caminho é a inovação, utilizando aulas mais interativas, que estimulem a participação dos alunos. Dessa forma esse projeto fomenta a introdução de conteúdos aliado ao uso de tecnologias digitais, buscando uma aula diversificada e facilitando 0 aprendizado. 


\section{REFERÊNCIAS BIBLIOGRÁFICAS}

AUSUBEL, D. P. Aquisição e Retenção de Conhecimentos: uma perspectiva cognitiva. Lisboa: Plátano, 2000.

BRASIL. Lei de Diretrizes e Bases da Educação Nacional, Lei no 9394, 20 de dezembro de 1996.

BRASIL. Ministério da Educação. Secretaria de Educação Básica. Biologia: catálogo do Programa Nacional do Livro para o Ensino Médio, PNLEM/2009. Brasília: Fundo Nacional de Desenvolvimento da Educação, 2009.

BRASIL. Ministério da Educação. Secretaria da Educação Média e Tecnológica. Parâmetros Curriculares Nacionais + $(\mathrm{PCN}+)$ - Ciências da Natureza e suas Tecnologias. Brasília: MEC, 2002.

BRASIL, Ministério da Educação, Secretaria de Educação Básica. Orientações Curriculares para o Ensino Médio: Ciências da Natureza, Matemática e suas Tecnologias. Brasilia: Ministério da Educação, 2006. p. 34. Acessado em: 09 de março 2020.

. Lei no 13.005 , de 25 de junho de 2014. Aprova o Plano Nacional de Educação - PNE. Brasília. Disponível em: http://pne.mec.gov.br/. Acessado em: 06 de maio 2020.

BRUSCA, R. \& BRUSCA, G.J. Invertebrados. $2^{\text {a }}$ ed. Editora Guanabara Koogan S.A., Rio de Janeiro, 2007.

COELhO, Maurício, 0 QR Code: o que é e como usar. Disponível em: https:// <Tecnologia iG @ https://tecnologia.ig.com.br/dicas/2013-03-04/qr-code-0-que-e-e-como-usar.html〉. Acessado em: 04 de out 2019.

FIGUEIRED0, M. Z. A.; CHIARI, B. M.; GOULART, B. N. G. Discurso do Sujeito Coletivo: uma breve introdução à ferramenta de pesquisa qualiquantitativa. Distúrbios da Comunicação, São Paulo, v. 25, n. 1, p. 129-136, abr. 2013.

INFOGRÁFICOTECMUNDO.Dispnívelem: https://img.ibxk.com.br//2013/3/infograficos/37372/infograficotecmundo-373720.jpg?v=64, 2013. Acessado em: 08 de mai de 2020.

KRASILCHIK, M. Práticas de Ensino de Biologia. $4^{\text {a }}$ ed. ver. e amp.,l ${ }^{\text {a }}$ reimp. - São Paulo: Editora da Universidade de São Paulo, 2005.

LEFÈVRE, F.; LEFÈVRE, A. M. C; TEIXEIRA, J. J. V. 0 discurso do sujeito coletivo: uma nova abordagem metodológica em pesquisa qualitativa. Caxias do Sul: EDUCS, 2000.

MAGARÃo, J. F. L., STRUCHINER, M., GIANNELLA, T. Potencialidades Pedagógicas dos audiovisuais para o ensino de ciências: uma análise dos recursos disponíveis no portal do professor. III Encontro Nacional de Ensino de Ciências da Saúde e do Ambiente, Niterói/RJ, 2012.

MORAES, G. P. Uma reflexão sobre o currículo mínimo de biologia do Estado do Rio de Janeiro, 2016, Rio de Janeiro. Disponivel em: http://www.unirio.br/ppgedu/DissertaoPPGEduGERSONPEREIRAMORAES.pdf. Acessado em: 01 de set 2018 .

MOURA, A. Geração Móvel: um ambiente de aprendizagem suportado por tecnologias móveis para a "Geração Polegar". In P. Dias, A. J. 0sório (org.) Actas da VI Conferência Internacional de TIC na Educação Challenges 2009 / Desafios 2009. Braga: Universidade do Minho. 50-78. 2009ª.

QRCODE. Qrcode / denso wave. Disponível em: 〈https://www.qrcode.com/en/history/> Acessado em 08 de mai 2020.

RAZERA, J. C. C.; BATISTA, R. M. S; SANTOS, R. P. Informática no ensino de biologia: limites e possibilidades de uma experiência sob a perspectiva dos estudantes Experiências em Ensino de Ciências. v. 2, 2007.

RI0 DE JANEIR0. Currículos Mínimos 2012 - Ciências e Biologia. Governo do Estado do Rio de Janeiro. Secretaria de Estado de Educação, Rio de Janeiro, 2012.

RUPPERT, E.E.; FOX, R.S.; BARNES R.D. Zoologia dos Invertebrados: uma abordagem funcional - evolutiva, $7^{\mathrm{a}}$ ed. São Paulo: Roca, 2005. 
0 Uso da Tecnologia QR Code e de Outros Recursos Digitais em Estudos de Invertebrados

SACRISTÀN, J.G. 0 que significa o currículo? Saberes e incertezas sobre o currículo. Porto Alegre: Penso, 2013. SERRES, M. Polegarzinha. Tradução de Jorge Bastos. Rio de Janeiro: Bertrand Brasil, 2013.

ZABALA, Antoni. A prática educativa: como ensinar. Porto Alegre: Artmed, 1998. 